\title{
Improvement of growth rate and cell productivity by aeration rate in cultures of the marine microalga Dunaliella tertiolecta
}

Fabregas, J., Ferron, L., Gammallo, Y., Vecino, E., Otero, A., Herrero, C.

Departamento de Microbiologia, Facultad de Farmacia, Universidad de Santiago, E-15706

Santiago, Spain

\section{Bioresource Technology}

Volume 48, Issue 2, 1994, Pages 107-111

DOI: $10.1016 / 0960-8524(94) 90196-1$

\section{Abstract}

The effect of different aeration rates and $\mathrm{CO}_{2}$ supply regimes on mass cultures of the marine microalga Dunaiella tertiolecta was studied. Eight aeration rates in the range 06.51 litres of air $\min ^{-1}$ litre of culture ${ }^{-1}$ were tested. The results were compared to those obtained in non-aerated cultures into which pure $\mathrm{CO}_{2}$ was introduced and to cultures into which air enriched with $\mathrm{CO}_{2}$ was bubbled. The growth rate and final cellular density of $D$. tertiolecta in a sea-water-based medium increased with the aeration rate in the culture vessel. The maximal cellular density was $12.46 \times 10^{6}$ cells $\mathrm{ml}^{-1}$ under an air flow rate of 6.51 litres $\mathrm{min}^{-1}$ litre of culture ${ }^{-1}$, but evaporation and salinity increased sharply at this high aeration rate. The final cell density was proportional to the air flow rate and $\mathrm{CO}_{2}$ following the range (figures being litres of air $\mathrm{min}^{-1}$ litre of culture ${ }^{-1}$ ): $6.51=3.72>$ $1.86>\mathrm{CO}_{2}=\left(0.93+\mathrm{CO}_{2}\right)>0.93>0.46>0.23>0.11>0$ (Mann-Whitney test $\mathrm{p}<$ 0.05). When $\mathrm{D}$. tertiolecta was grown under a $\mathrm{CO}_{2}$ supply within the optimal $\mathrm{pH}$ levels but without aeration the cultures reached a cell density of $7 \times 10^{6}$ cells $\mathrm{ml}^{-1}$. D. tertiolecta growth rate was inversely proportional to $\mathrm{pH}$, the upper boundary for maximal growth rate being $\mathrm{pH}$ 9.2. Oxygen in the culture media produced by the photosynthetic activity of the microalgae did not inhibit growth. The dissolved $\mathrm{CO}_{2}$ concentration in seawater was the limiting factor for $\mathrm{D}$. tertiolecta growth. At a $\mathrm{pH}$ value 
of 8.3, D. tertiolecta was not able to take up carbon in the form of carbonates dissolved in seawater.

The effect of different aeration rates and $\mathrm{CO}_{2}$ supply regimes on mass cultures of the marine microalga Dunaiella tertiolecta was studied. Eight aeration rates in the range 06.51 litres of air $\min ^{-1}$ litre of culture ${ }^{-1}$ were tested. The results were compared to those obtained in non-aerated cultures into which pure $\mathrm{CO}_{2}$ was introduced and to cultures into which air enriched with $\mathrm{CO}_{2}$ was bubbled. The growth rate and final cellular density of $D$. tertiolecta in a sea-water-based medium increased with the aeration rate in the culture vessel. The maximal cellular density was $12.46 \times 10^{6}$ cells $\mathrm{ml}^{-1}$ under an air flow rate of 6.51 litres $\mathrm{min}^{-1}$ litre of culture ${ }^{-1}$, but evaporation and salinity increased sharply at this high aeration rate. The final cell density was proportional to the air flow rate and $\mathrm{CO}_{2}$ following the range (figures being litres of air $\mathrm{min}^{-1}$ litre of culture ${ }^{-1}$ ): $6 \cdot 51=3 \cdot 72$ $>1 \cdot 86>\mathrm{CO}^{2}=\left(0 \cdot 93+\mathrm{CO}_{2}\right)>0 \cdot 93>0 \cdot 46>0 \cdot 23>0 \cdot 11>0$ (Mann-Whitney test $\mathrm{p}<0 \cdot 05)$. When $\mathrm{D}$. tertiolecta was grown under a $\mathrm{CO}_{2}$ supply within the optimal $\mathrm{pH}$ levels but without aeration, the cultures reached a cell density of $7 \times 10^{6}$ cells $\mathrm{ml}^{-1}$. D. tertiolecta growth rate was inversely proportional to $\mathrm{pH}$, the upper boundary for maximal growth rate being $\mathrm{pH} 9 \cdot 2$. Oxygen in the culture media produced by the photosynthetic activity of the microalgae did not inhibit growth. The dissolved $\mathrm{CO}_{2}$ concentration in seawater was the limiting factor for $\mathrm{D}$. tertiolecta growth. At a $\mathrm{pH}$ value of $8 \cdot 3$, D. tertiolecta was not able to take up carbon in the form of carbonates dissolved in seawater.

\section{Author keywords}

Aeration; Carbonates; $\mathrm{CO}_{2}$; Dunaliella tertiolecta; Mass culture; Microalgae; $\mathrm{pH}$

\section{Indexed keywords}

Engineering controlled terms: Algae; Carbon dioxide; Growth kinetics; Marine biology; pH effects; Productivity; Seawater; Substrates; Water aeration

Engineering uncontrolled terms: Aeration rate; Dunaliella tertiolecta

Engineering main heading: Plant cell culture

EMTREE drug terms: carbon; carbon dioxide; carbonic acid derivative; oxygen; sea water; sodium chloride 
EMTREE medical terms: aeration; airflow; article; cell culture; cell density; cell growth; culture medium; growth rate; nonhuman; ph; photosynthesis; phytoplankton; priority journal; productivity

\section{INTRODUCTION}

Species of the genus Dunaliella are being commercially cultured for various purposes. Glycerol, $\beta$-carotene and protein-enriched biomass can be produced from the genus Dunaliella (Gibbs \& Duffus, 1976; BenAmotz \& Avron, 1978, 1980; Ben-Amotz et al., 1982; Borowitzka, 1991 ). Dunaliella tertiolecta can also be used as a source of SCP (Fabregas \& Herrero, 1985 ) and as a mineral supplement in fish feed (Fabregas \& Herrero, 1986). One of the most characteristic features of this species is the lack of a rigid cell wall (Oliveira et al., 1980) which makes its digestion easier. Recently its use as a health food and its anti-cancer effect have been studied (Mokady, 1992; Fuji etal., 1993).

One of the factors limiting growth-rate in cultures of $D$. tertiolecta is $\mathrm{pH}$. When the source of nitrogen is $\mathrm{NaNO}$ ) the $\mathrm{pH}$ level in the medium increases as a consequence of microalgal metabolic activity. One of the ways of keeping the $\mathrm{pH}$ within an optimal range for maximal growth rate is the sparging of pure $\mathrm{CO}_{2}$ or $\mathrm{CO}_{2}$ and air (air by itself contains 0 '03\% of $\mathrm{CO}_{2}$ ) at different rates. The supply of $\mathrm{CO} 2$ is one of the main items in the calculation of costs in mass cultures of microalgae. In the present work the optimization of air flow without any $\mathrm{CO}_{2}$ supplementation was investigated in order to achieve maximal growth rate and final cell density.

\section{METHODS}

The marine microalga Dunaliella tertiolecta was grown in sea-water previously filtered through fibre glass (GF/C), autoclaved and enriched with the commercial inorganic nutrient Algal-1 (Nutrición Avanzada SA. Avda Cortes 8. Fuentes Nuevas. Ponferrada. Leon. Spain) (Herrero et al., 1991 ) in which the source of nitrogen was $2 \mathrm{mM} \mathrm{NaNO}_{3}$. The initial $\mathrm{pH}$ of the cultures was $8^{\prime} 1$ and the initial salinity was $3{ }^{\prime} 5 \%$.

The cultures were grown in 6 litre flasks containing 4.3 litres of medium at $18^{\circ} \mathrm{C}$ under a light intensity of $81.04 \mu \mathrm{E} \mathrm{m} \mathrm{m}^{-2} \mathrm{~S}^{-1}$ and a ljght periodicity of $12: 12 \mathrm{~h}$ light: darkness. 
The initial inoculum density was $5 \times 10^{5}$ cells $\mathrm{ml}^{-1}$ from an exponentially growing culture.

Seven different flows of air were applied to the cultures: $0.11,0.23,0.46,0.93,1.86$, $3 \cdot 72,6.51$ litres of air min $^{-1}$ litre of culture ${ }^{-1}$. Two controls were set up as follows: one without aeration (named as air flow 0) and another with no aeration to which different quantities of $\mathrm{CO}_{2}$ were added by sparging twice a day in order to keep the $\mathrm{pH}$ in the range 7.2-7.9. A third control was aerated at 0.93 litres of air $\mathrm{min}^{-1}$ litre of culture-I with an intermittent supply of $\mathrm{CO}_{2}$ to keep the $\mathrm{pH}$ in this same range. Two replicates were set for each condition. The diameter of the aeration line through which air and $\mathrm{CO}_{2}$ were bubbled was $6 \mathrm{~mm}$.

The cell density was determined daily using an improved Neubauer haemacytometer. The $\mathrm{pH}$ was measured using a portable Radiometer model 80 and an Ingold U455 pH electrode. The dissolved oxygen was measured with an Orion oxygen electrode (Model

97-08) and the total salinity with an Atago S/Mill refractometer.

Dissolved $\mathrm{O}_{2}$, salinity (\%) and $\mathrm{pH}$ were measured daily in the cultures. The $\mathrm{pH}$ and oxygen levels were measured between 1.3 and $2 \mathrm{~h}$ from the beginning of the light periods. In the cultures under pure $\mathrm{CO}_{2}$ the $\mathrm{pH}$ was also measured after $5-6 \mathrm{~h}$ of light period and $\mathrm{CO}_{2}$ was added if necessary. The salinity was corrected with distilled water when values reached $4.0 \%$. Distilled water was added slowly to avoid the formation ofstrong salinity gradients.

The growth rates were calculated from linear regression analyses of average cell density values during the exponential phase using the method proposed by Guillard (1973). Final cell densities were compared using the non-parametric statistics (MannWhitney test).

\section{RESULTS}

The salinity in aerated cultures was increased by evaporation during the 12 days of culture. Aerations between 0 and 0.23 litre $\min ^{-1}$ litre of culture ${ }^{-1}$ caused a small increase in salinity, while aeration rates in the range $0.46-6.51$ litre $\min ^{-1}$ litre of culture ${ }^{-1}$ had higher increases in salinity (Table I ). In the cultures with aeration rates higher than 0.93 litre $\mathrm{min}^{-1}$ of culture ${ }^{-1}$, salinity exceeded $4.0 \%$ requiring the addition of distilled water to avoid the introduction of important variations from the initial conditions of the 
culture and to allow a correct calculation of cell density (Table 1), although at these aeration rates the stationary phase was reached before the maximum level of salinity.

In the present experiments, the highest amount of oxygen that remained dissolved in the culture was $14.7 \mathrm{ppm}$ recorded in the culture with only $\mathrm{CO}_{2}$ supplementation (Table 2 ), and this was caused by the absence of aeration. Oxygen concentration in the aerated cultures ranged between 5 and $9 \mathrm{ppm}$. Cultures under aeration flows of $0 \cdot 11$ 0.93 litre $\min ^{-1}$ litre of culture ${ }^{-1}$ had higher $\mathrm{O}_{2}$ values than those with aerations in the range 1.86-6.51 litres $\mathrm{min}^{-1}$ litre of culture ${ }^{-1}$. The culture under 6.51 litre $\mathrm{min}^{-1}$ litre of culture $^{-1}$ had, in general, the lowest oxygen values throughout the culture period (Table 2). In the nonaerated culture the oxygen level decreased due to the absence of photosynthetic activity.

The final cell density was proportional to the airflow rate and $\mathrm{CO}_{2}$ following the range (the figures show litres of air $\mathrm{min}^{-1}$ litre of culture ${ }^{-1}$ ): $6.51=3.72>1.86>\mathrm{CO}_{2}=(0.93$ $+\mathrm{CO}_{2}$ ) $>0.93>0.46>0.23>0.11>0$ (Mann-Whitney test $p<0.05$ ) (Fig. 1). Nonaerated cultures showed negligible growth. The control culture submitted to CO, additions without air (in order to keep the $\mathrm{pH}$ between 7.2 and 7.9) reached a final cell density of $7 \times 106$ cells $\mathrm{ml}^{-1}$, higher than those reached in cultures under aeration flows of $0-0.93$ litres $\min ^{-1}$ litre of culture ${ }^{-1}$, but lower than in the cultures with aeration flows between 1.86 and 6.51 . No significant difference $(p=0.82)$ in stationary-phase cell densities was recorded between the cultures under 0.93 litre $\min ^{-1}$ litre of culture ${ }^{-1}$ plus $\mathrm{CO}_{2}$ and cultures to which only $\mathrm{CO}_{2}$ was added. Maximal final densities were $11.32 \mathrm{x}$ $10^{6}$ cells $\mathrm{ml}^{-1}$ and $12,46 \times 10^{6}$, achieved with aeration rates of 3.72 and $6^{\prime} 51$ litres min ${ }^{1}$ litre of culture ${ }^{-1}$ respectively (Fig. I).

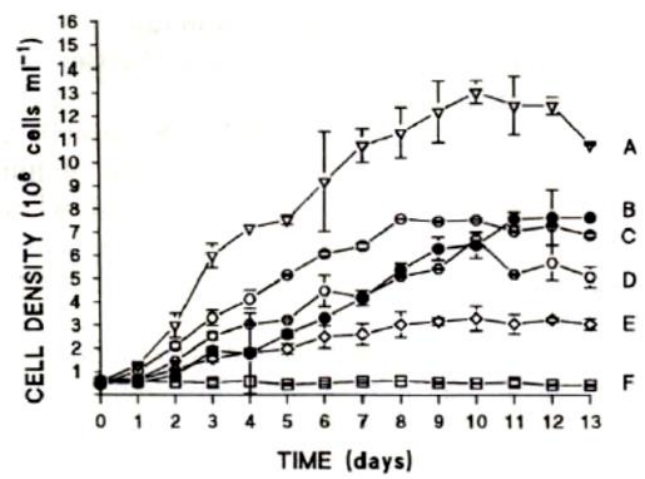

Fig. 1. Dunaliella tertiolecta growth curves under different aeration and $\mathrm{CO}_{2}$ supply regimes. For clarity only the curves for some of the conditions tested are drawn, the other curves were of similar shape and fell between the curves shown. The figures are expressed as litres of air min $^{-1}$ litre of culture ${ }^{-1}$. $\mathrm{A}, 6.51 ; \mathrm{B}, \mathrm{CO}_{2} ; \mathrm{C},\left(\mathrm{CO}_{2}+0.93\right)$; D, 0.93; E, 0.23; J, 0. Error bars represent standard deviations. 
An increase in the aeration rate caused a decrease in the $\mathrm{pH}$ and a proportional increase in the growth rate. The higher the aeration rates applied, the more $\mathrm{CO}_{2}$ would be transferred to the culture medium from the air, resulting in a decrease in the $\mathrm{pH}$ and a subsequent increase in growth rate (Table 3). Increasing cell density produced linear increases in $\mathrm{pH}$ during exponential growth in the aerated cultures $\left(r^{2}>0.9\right.$ except for the aeration rate 0.93 litre $\min ^{-1}$ litre of culture ${ }^{-1}$ for which $r^{2}=0^{\prime} 7$ ) (Fig. 2).

The maximal growth rate increased with aeration flow following a logistic curve, a maximum being reached at an aeration rate about 3.7 litres $\min ^{-1}$ litre of culture ${ }^{-1}$ (Fig. 3). The maximal growth rate of the culture under pure $\mathrm{CO}$, during the logarithmic phase was 0.94 day $^{-1}$, higher than the growth rate of the culture to which a mixture of air and CO, was bubbled: 0.82 day $^{1}$, and similar to the culture with air alone supplied at a rate of $0^{\prime} 93$ litre $\min ^{-1}$ litre of culture ${ }^{-1}$.

\section{DISCUSSION}

In cultures with high cell densities the oxygen produced by photosynthetic activity may reach concentrations as high as 35 ppm (Richmond, 1983). High concentrations of dissolved oxygen could be toxic for the cells thus resulting in a decrease in photosynthetic activity. However, the results in the cultures grown under pure $\mathrm{CO}_{2}$ supply, in which the oxygen concentration was very high (14 ppm) but the final density was $7 \times 10^{6}$ cells $\mathrm{ml}^{-1}$, were similar to those achieved in cultures with aeration rates of 0,93-1,86 litre $\mathrm{min}^{-1}$ litre of culture ${ }^{-1}$ (Fig. 1) where the dissolved oxygen was about $7-8$ ppm. This indicates that oxygen overload in the former cultures was not a limiting factor. Moreover, despite the high oxygen levels produced by microalgal growth during the first 3 days of the cultures under $\mathrm{CO}_{2}$ supply without air (8'2-14'7 ppm) the cultures doubled their cell density every $24 \mathrm{~h}$ (growth rate 0.94 days $^{-1}$ ), indicating again that the dissolved oxygen in the medium did not act as an important limiting factor for growth. 


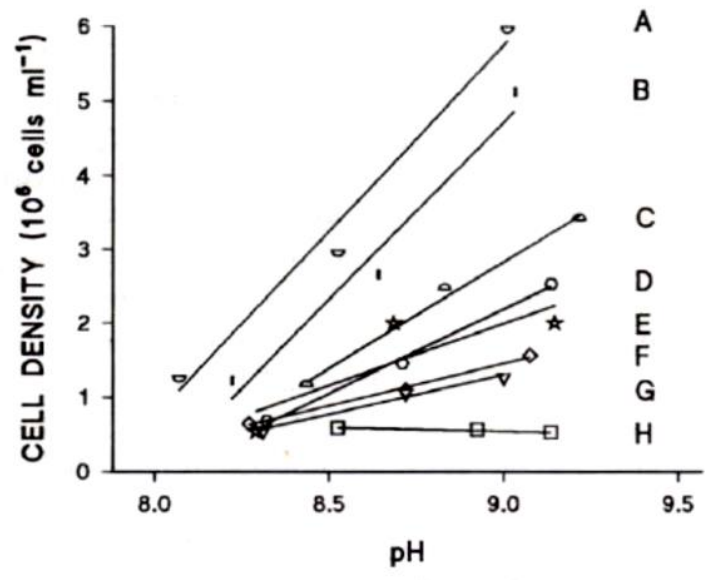

Fig. 2. Relationship between cell density, $\mathrm{pH}$ value and aeration rate during maximal growth-rate period in $D$. tertiolecta cultures (days 1-3). Linear regression lines are drawn $\left(r^{2}>0.9\right.$ except for aeration 0.93 litres of air $\min ^{-1}$ litre of culture $\left.^{-1}, r^{2}=0 \cdot 71\right)$. Aeration rate is expressed as litres of air $\min ^{-1}$ litre of culture ${ }^{-1}: \mathrm{A}, 6.51 ; \mathrm{B}, 3.72 ; \mathrm{C}, 1 \cdot 86 ; \mathrm{D}, 0.93$; E, $0 \cdot 46 ; \mathrm{F}, 0 \cdot 23 ; \mathrm{G}, 0 \cdot 11 ; \mathrm{H}, 0$.

In microalgal cultures, the $\mathrm{pH}$ is one of the main variables to be controlled in order to achieve the maximal growth rate. The metabolic activity of microalgae increases the $\mathrm{pH}$ of the medium when the source of nitrogen is nitrate. On the other hand, in aerated cultures, the CO, present at $0^{\prime} 033 \%$ in air (Warburg, 1919) tends to decrease the $\mathrm{pH}$ through the buffer system $\mathrm{H}_{2} \mathrm{CO}_{3}-\mathrm{CO}_{2}$. An equilibrium between the increase of $\mathrm{H}$ derived from algal growth and $\mathrm{CO}$, input should be pursued in order to maintain a constant $\mathrm{pH}$ during culture growth. In another marine microalgal species, Tetraselmis suecica, the specific growth rate is increased proportionally with $\mathrm{CO}_{2}$ (Molina et al., 1990). D. tertiolecta growth was influenced by $\mathrm{CO}_{2}$ concentration, provided by the different aeration rates, in the same way as has been described for the microalga Chlorella vulgaris (Markl, 1977).

Taking into account the total amount of $\mathrm{CO}_{2}$ contained in the bubbled air, more than three times as much $\mathrm{CO}_{2}$ was bubbled into the culture under an air flow of 0.93 litre min- I litre of culture- I than into the culture with pure $\mathrm{CO}_{2}$ during the culture period to achieve even lower final cell densities in the former (Table 4), which demonstrated that the efficiency of $\mathrm{CO}_{2}$ transfer from air was lower than the efficiency of the addition of pure $\mathrm{CO}_{2}$.

All the cultures reached a $\mathrm{pH}$ value of 9.2 by the third day of culture, even though the growth rates, and therefore the cell densities, during this period were different for each culture and proportional to the aeration. During this period maximal growth rate was recorded for all cultures, decreasing once a $\mathrm{pH}$ value of 9.2 was reached, except for an aeration rate of 1.86 for which maximal growth rate was recorded between days 0 and 
2. A similar high $\mathrm{pH}$ boundary of 9.3 was also described by Goldman et al. (1982). The growth rate and final cell density of $D$. teniolecta cultures depended on the $\mathrm{pH}$ of the culture. There was a linear relation between the $\mathrm{pH}$ increase and the increase in microalgal growth during the early logarithmic phase of growth (Fig. 2).

Despite the increase in maximal growth rate being linear up to an air flow of 0.93 litre $\min ^{-1}$ litre of culture ${ }^{-1} \quad\left(r^{2}=0^{\prime} 99\right)$, when the final density is considered the linear relationship was retained only up to about 0-46 litre $\min ^{-1}$ litre of culture ${ }^{-1}\left(r^{2}=0\right.$ '89) (Fig. 3). No statistically significant difference was recorded in the final cell density for aeration rates of 3.72 and 6.51 litres $\min ^{-1}$ litre of culture ${ }^{-1}$ (Mann-Whitney test, $p=0^{\prime} 2$ ), although the values for the latter aeration rate were slightly higher. A higher standard deviation for stationary-phase values of the cultures under the highest air flow may indicate a lower capacity of the cells to survive under starvation conditions, probably due to the lower content of storage substances.

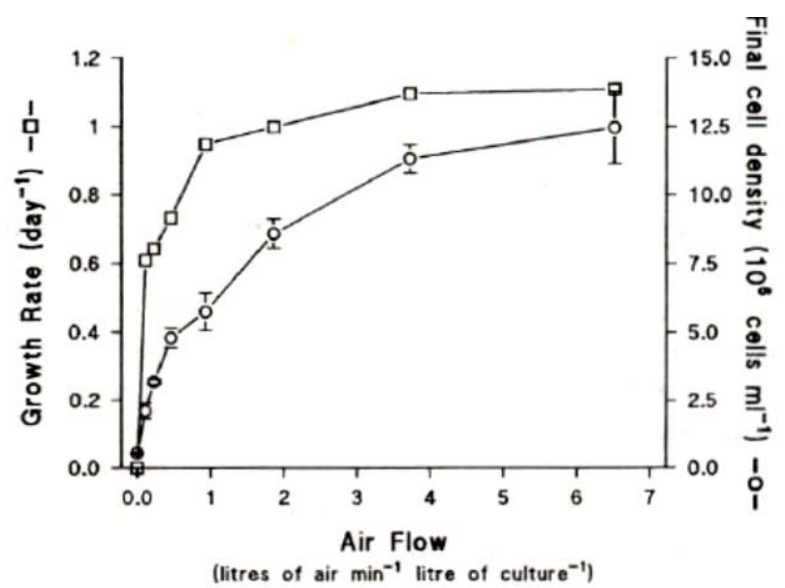

Fig. 3. Dunaliella tertiolecta maximal growth rate and final cell density obtained with different aeration rates. Growth rates were calculated as the slopes of linear regression fitting of data $\left(r^{2}>0.99\right)$ on increase in cell density from days 1 to 3 for all cultures except for air flow 1.86 litres of air $\mathrm{min}^{-1}$ litre of culture ${ }^{-1}$, for which maximal growth rate was recorded between days 0 and 2 . Error bars represent standard deviations.

The final cell density increased up to an aeration rate of 3.72 litres although the culture seemed to be $\mathrm{CO}_{2}$ saturated at an aeration rate around 0.93 litre $\mathrm{min}^{-1}$ litre of culture ${ }^{-1}$, as in the culture under pure $\mathrm{CO}_{2}$ the final cell density was between those obtained with 0.93 and 1.86 litres $\mathrm{min}^{-1}$ litre of culture ${ }^{-1}$, and there was no significant difference in the final cell density between the culture with the $\mathrm{CO}_{2}$ supply withoutair and the one with 0.93 litre $\mathrm{min}^{-1}$ litre of culture ${ }^{-1}$ supplemented with $\mathrm{CO}_{2}$, It is therefore possible that the growth of $D$. tertiolecta did not depend on $\mathrm{pH}$ and $\mathrm{CO}_{2}$ concentration alone. It would be logical to suppose that turbulence as a result of air flux, producing different movement regimes of the cells within the media under an equal light intensity, could be an 
important factor. The effect of turbulence and the importance of the flashing effect have been studied recently (Grobbelaar, 1991). It may be possible that there would be a different internal pool of limiting inorganic nutrient for each aeration regime. In this way, the higher the aeration the lower the intracellular pool needed for division resulting in a higher number of cells and/or a change of the cellular weight or volume.

\begin{tabular}{|c|c|c|c|c|c|c|c|c|c|}
\hline & \multirow[t]{2}{*}{$\mathrm{CO}_{2}$} & \multicolumn{8}{|c|}{$\begin{array}{c}\text { Air flow } \\
\left(\text { litres of air } \min ^{-1} \text { litre of culture }\right. \\
-1)\end{array}$} \\
\hline & & 0 & 0.11 & $0 \cdot 23$ & 0.46 & 0.93 & 1.86 & 3.72 & 6.51 \\
\hline & & & & & $\mathrm{p}$ & & & & \\
\hline \multicolumn{10}{|l|}{ Day } \\
\hline 0 & 8.44 & $8 \cdot 39$ & $8 \cdot 50$ & $8 \cdot 52$ & 8.52 & $8 \cdot 51$ & $8 \cdot 38$ & $8 \cdot 19$ & $8 \cdot 14$ \\
\hline 1 & & $8 \cdot 54$ & $8 \cdot 31$ & $8 \cdot 27$ & $8 \cdot 29$ & $8 \cdot 32$ & $8 \cdot 44$ & $8 \cdot 22$ & 8.07 \\
\hline 2 & 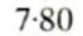 & 3 & 8.73 & 8.72 & 8.69 & $8 \cdot 71$ & 8.83 & $8 \cdot 64$ & 8.53 \\
\hline 3 & & 4 & $9 \cdot 00$ & $9 \cdot 08$ & $9 \cdot 15$ & $9 \cdot 14$ & $9 \cdot 22$ & 9.03 & $9 \cdot 01$ \\
\hline 4 & 8.3 & $9 \cdot 11$ & 8.78 & $8 \cdot 83$ & $8 \cdot 85$ & $8 \cdot 74$ & $8 \cdot 83$ & 8.75 & $8 \cdot 70$ \\
\hline 5 & $8 \cdot 00$ & $9 \cdot 08$ & 8.66 & $8 \cdot 81$ & $8 \cdot 80$ & 8.75 & 8.78 & 8.71 & 8.66 \\
\hline 6 & 8.39 & $9 \cdot 18$ & $9 \cdot 00$ & $9 \cdot 05$ & $9 \cdot 13$ & $9 \cdot 11$ & $9 \cdot 04$ & 8.86 & 8.87 \\
\hline 7 & $7 \cdot 41$ & $9 \cdot 09$ & 8.89 & $8 \cdot 89$ & 8.74 & 8.62 & $8 \cdot 57$ & 8.47 & $8 \cdot 42$ \\
\hline 8 & $8 \cdot 18$ & $9 \cdot 18$ & 8.99 & $9 \cdot 10$ & 9.09 & $9 \cdot 07$ & $8 \cdot 90$ & 8.71 & $8 \cdot 61$ \\
\hline 9 & $7 \cdot 67$ & $9 \cdot 16$ & 8.93 & $9 \cdot 04$ & 8.97 & 8.85 & $8 \cdot 78$ & $8 \cdot 62$ & $8 \cdot 38$ \\
\hline 10 & $8 \cdot 10$ & $9 \cdot 23$ & 8.95 & $9 \cdot 04$ & 8.96 & 8.93 & $8 \cdot 80$ & 8.69 & $8 \cdot 42$ \\
\hline 11 & $8 \cdot 00$ & $9 \cdot 20$ & 8.94 & 8.99 & 8.92 & 8.93 & $8 \cdot 75$ & $8 \cdot 40$ & $8 \cdot 40$ \\
\hline 12 & $7 \cdot 56$ & $9 \cdot 19$ & 8.90 & $8 \cdot 82$ & $8 \cdot 81$ & 8.70 & 8.63 & 8.43 & $8 \cdot 14$ \\
\hline
\end{tabular}

D. tertiolecta adapts proportionally and readily to changes in the availability of dissolved inorganic carbon by the induction of high affinity/high capacity $\mathrm{CO}_{2}$ concentrating systems (CCMS) (Miyachi el al., 1985; Aizawa el al., 1986; Coleman, 1991). $\mathrm{CO}_{2}$ is converted from $\mathrm{HCO}_{3}$ via carbonic anhydrase (CA) located at the cell surface (Aizawa \& Miyachi, 1984; Aizawa el al., 1986). Although the ability of Dunaliella to take up bicarbonate has been described (Burns \& Beardall, 1987), 14C incorporation studies have demonstrated that the microalga appeared to utilize free carbon dioxide during the mid-exponential phase (Mukerji el al., 1977). Our results agree with the latter, as the non-aerated culture showed no increase in cell density. The level of dissolved carbonates in sea-water is high enough to support growth, which indicates that limitation is caused by the absence of dissolved $\mathrm{CO}_{2}$ It can be concluded that at a $\mathrm{pH}$ of 8.3 the microalga cannot utilize carbonates as a source of carbon. It could have been possible that the $\mathrm{CA}$ activity was inhibited at high $\mathrm{pH}$, thus limiting growth rate. The optimal aeration rate would be the one defining the highest growth rate and highest final cell density with the lowest air flow and evaporation. No culture fulfilled all these conditions, but an equilibrium among these characteristics can be established by choosing an aeration rate of $0.93{\text { litre } \mathrm{min}^{-1} \text { litre of culture }}^{-1}$ (Table 4). 
Table 4. (A) Air supplied per day and litre of culture $\left(\times 10^{3}\right)$. (B) Days to reach the stationary phase. (C) Total volume of air $\left(\times 10^{3}\right)$ supplied per litre of culture during the period of growth (from items $\mathrm{A}$ and $\mathrm{B}$ ). (D) $\mathrm{CO}_{2}$ supply per litre of culture (litres/ day) $\left(0.33 \%\right.$ of $\mathrm{CO}_{2}$ in the air is considered for the calculations in aerated cultures). (E) Total volume of $\mathrm{CO}_{2}$ (litres) supplied during the period of growth (from items $B$ and $E$ ). (F) Final cell density (cells $/ \mathrm{ml} \times 10^{6}$ )

\begin{tabular}{|c|c|c|c|c|c|c|c|c|c|}
\hline & \multirow[t]{2}{*}{$\mathrm{CO}_{2}$} & \multicolumn{8}{|c|}{ Air flow (litres of air $\min ^{-1}$ litre of culture ${ }^{-1}$ ) } \\
\hline & & 0 & $0 \cdot 11$ & $0 \cdot 23$ & $0 \cdot 46$ & 0.93 & $1 \cdot 86$ & $3 \cdot 72$ & $6 \cdot 51$ \\
\hline A & 0 & 0 & $0 \cdot 158$ & $0 \cdot 331$ & $0 \cdot 662$ & $1 \cdot 339$ & 2.678 & $5 \cdot 356$ & $9 \cdot 374$ \\
\hline B & 11 & 0 & 4 & 10 & 11 & 10 & 10 & 9 & 8 \\
\hline $\mathrm{C}$ & 0 & 0 & 0.633 & $3 \cdot 312$ & $7 \cdot 286$ & $13 \cdot 392$ & $26 \cdot 781$ & $18 \cdot 211$ & 74.995 \\
\hline D & 0.125 & 0 & $0 \cdot 047$ & 0.099 & $0 \cdot 198$ & 0.401 & 0.803 & 1.607 & 2.812 \\
\hline E & $1 \cdot 381$ & 0 & $0 \cdot 190$ & 0.993 & $2 \cdot 185$ & $4 \cdot 017$ & 8.035 & 14.463 & 22.499 \\
\hline $\mathrm{F}$ & $7 \cdot 0$ & 0.55 & $2 \cdot 11$ & $3 \cdot 18$ & $4 \cdot 79$ & $5 \cdot 75$ & $8 \cdot 59$ & $11 \cdot 32$ & $12 \cdot 46$ \\
\hline
\end{tabular}

\section{ACKNOWLEDGEMENT}

This work was supported by the Community Research Program in the Fisheries Sector (FAR) of the European Community (EC) by the project number:AQ.2.494.

\section{REFERENCES}

Aizawa. B. \& Miyachi, S. (1984). Carbonic anhydrase located on cell surface increases the affinity for organic carbon in photosynthesis of Dunaliella tertiolecta. FEBS Leuers, 173, 41-4.

Aizawa, K., TSllzuki, M. \& Miyachi, S. (1986). Kinetic studies on the active species of inorganic carbon absorbed by the cells of Dunaliella tertiolecta. Plant Cell Physiol., 27 ( I ),37-47.

Ben-Amozt, A. \& Avron, M. (1978). On the mechanism of osmorregulation in Dunaliella. In Energetics and Structure of Halophilic Microorganisms, ed. S. R. Kaplan \& M. Ginzburg. Elsevier/North Holland/Biomedical Press, Amsterdam, pp. 529-41.

Ben-Amotz, A. \& Avron, M. (1980). Glycerol, p-carotene and dry algal meal production by commercial cultivation of Dunaliella. In Algae Biomass: Production and Use, ed. G. Shelef \& c. J. Soeder. Elsevie r/North Hoiland /Biomedical Press, Amsterdam, pp. 603-10.

Ben-Amotz, A., Sussman, I. \& Avron, M. ( 1982). Glycerol production by Dunaliella. Experientia, 38, 49-52.

Borowitzka, L. J. (1991). Development of Western Biotechnology's algal p-carotene plant. Biares. Technol., 38, 251 -2.

Burns, B. D. \& Beardall, J. (1987 ). Utilization of inorganic carbon by marine microalgac. 1. Exp. Mar. Biol. Eco/., 107,75-86.

Coleman, J. R. (1991). The molecular and biochemical analyses of CO2-concentrating mechanisms in cyanobacteria and microalgae. Plam Cell Environ., 14,86 1-7.

Fabregas, J. \& Herrero, C. (1985). Marine microalgae as a potential source of single cell protein. Appli Microbiol. Biotechnol., 13, 1032-3.

Fabregas, J. \& Herrero, C. (1986). Marine microalgae as a potential source of minerals in fish diets. Aquaculture, 51, 237-43. 
Fujii, Y, Sakamoto, S., Ben-Arnalz, A. \& Nagasawa. H. (1993). Effects of beta-carotene rich algae Dunaliella bardawil on the dynamic changes of normal and neoplastic mammary cells and general metabolism in mice. Amicallc. Res., 13 (2), 389-93.

Gibbs, N. \& Duffus, C. N. (1976). Natural protoplast Dunaliella as source of protein. Appl. Environ. Microbiol, $31,602-4$.

Goldman. J. c., Azov, Y .. Riley, C. B. \& Dennet, M. R. (1982). The effect of pH in intensive microalgal cultures. I. Biomass regulation. J. Expo Mar. Bioi. Ecol., 57, 1- 13.

Grobbelaar, J. U. (1991). The influence of light/dark cycles in mixed algal cultures on their productivity. Biores. Tech-1101.,38, 189-94.

Guillard, R. L. (1973). Division rates. In Halldbook of Phycological Methods. Culture methods and Growth measurements, ed. J. R. Stein. Cambridge University Press, London. pp. 290-31 I.

Herrero, C., Cid, A., Fabregas, J. \& Abalde, J. (1991 ). Yields in biomass and chemical constituents for four commercially important marine microalgae with different culture media. Aquaculture Engng., 10,99-110.

Markl, H. (1977). CO2 transport and photosynthetic productivity of a continuous culture alga. Biotechnol. Bioengng, XIX, 185 1-62.

Miyachi, S., Tsuzuki, M. \& Yagawa, Y. (1985). Carbonic anhydrase in various microalgae. In Inorcanic Carbon Uptake by Aquatic Photosynthetic Organisms, ed. W. Lucas \& J. Berry. The American Society of Plant Physiologists, Rockville, MD, pp. 145- 54.

Mokady, S. (1992). Nutritional, toxicological and therapeutic aspects. In Dunaliella: Physiology, Biochemistry and Biotechnology, cd. M. Avron \& A. Ben-Amo tz. CRe Press. Boca Raton, FL, p. 217.

Molina, E., Martinez, Ma., Sanchez, S., García F. \& Contreras. A. (1990). The influence of flow rate and the composition of supplied $\mathrm{CO} 2 /$ air mixtures on discontinuous growth of Tetraselmis sp. Appl. Microbiol. Bioteccnol., 34, 103-7.

Mukerijii, D., Glover, H. E. \& Morris, I. ( 1977). Diversity in the mechanism of carbon dioxide fixation in Dunaliella tertiolecta (Chlorophyceae). J. Phycol., 14 (2), 137-42.

Oliveira, L., Bisalputra, T. \& Antia, N. J. (1980). Ultrastructural observation of the surface coat of Dunaliella tertiolecta from staining with cationic dyes and enzyme treatments. New Phytol., 85, 375-92.

Richmond, A. (1983 ). Phototrophic microalgae. In Biotechnology, Vol. 3, ed. H. J. Rehm \& F. Reed. Verlag Chemie, Weinheim, p. 10.

Warburg, O. ( 1919). Uber die Geschwindigkeit der photochemischen Kohlensaurezersetzung in lebenden Zellen. Biochim. Acta, 100,230-70. 